A C G

Rec. Nat. Prod. 13:1 (2019) 24-36

records of natural

publications

products

\title{
Biological Activities of Various Extracts from Salvia cassia Sam. ex Rech.f. and Chemical Composition of Its Most Active Extract
}

\author{
Burcu Sen Utsukarci $^{1 \oplus}$ *, Bahar Gurdal ${ }^{2 \oplus}$, Merve Bilgin ${ }^{3 \oplus}$, Dilek Satana ${ }^{4 \oplus}$, \\ Betul Demirci $^{5 \oplus}$, Nur $\operatorname{Tan}^{1 \oplus}$ and Afife Mat $^{1 \oplus}$ \\ ${ }^{1}$ Faculty of Pharmacy, Department of Pharmacognosy, Istanbul University, Istanbul 34116, Türkiye \\ ${ }^{2}$ Faculty of Pharmacy, Department of Pharmaceutical Botany, Istanbul University, Istanbul 34116, \\ Türkiye \\ ${ }^{3}$ Faculty of Pharmacy, Department of Pharmaceutical Microbiology, Istanbul Yeni Yuzyil University, \\ Istanbul 34010, Türkiye \\ ${ }^{4}$ Faculty of Medicine, Department of Microbiology and Clinical Microbiology, Istanbul University, \\ Istanbul 34093, Türkiye \\ ${ }^{5}$ Faculty of Pharmacy, Department of Pharmacognosy, Anadolu University, Eskisehir 26470, Türkiye
}

(Received February 23, 2018; Revised March 30, 2018; Accepted April 01, 2018)

\begin{abstract}
This study was conducted on the antibacterial, antimycobacterial and antifungal activities of various extracts (petroleum ether $(\mathrm{PE})$, chloroform $\left(\mathrm{CHCl}_{3}\right)$ and ethanol $(\mathrm{EtOH})$ extracts; infusion and decoction) and essential oil from the aerial parts of S. cassia Sam. ex Rech.f. and the chemical composition of the most active samples. The antibacterial activity was determined against Bacillus subtilis, Staphylococcus aureus, methicillin resistant Staphylococcus aureus, Pseudomonas aeruginosa, Enterococcus faecalis, Klebsiella pneumoniae, Proteus mirabilis and Escherichia coli. The antimycobacterial activity was analyzed against five different Mycobacterium tuberculosis and the antifungal activity was compared with two dermotophytes and three Candida species. The composition of EO was analyzed by GC-FID and GC-MS. The EO had a very good activity against B. subtilis ( 0.3 $\mu \mathrm{L} / \mathrm{mL}$ ) and good activity against $S$. aureus, methicillin resistant $S$. aureus (MRSA) and E. faecalis $(0.6 \mu \mathrm{L} / \mathrm{mL})$. All extracts were active in the antimycobacterial and antifungal tests (MICs $=50-400 \mu \mathrm{g} / \mathrm{mL}$ ). The EO was the most active samples against all Mycobacterium strains, dermatophytes and Candida species (MICs=0.1-6.25 $\mu \mathrm{L} / \mathrm{mL}$ ). Because of the high activity of EO, its composition was analyzed, and the major compound was found caryophyllene oxide $(22.3 \%)$, which was also found the major components of the essential oils from other antimicrobial plants such as Salvia trichoclada Benth.
\end{abstract}

Keywords: Salvia cassia; antimicrobial; antimycobacterial; antifungal; essential oil; caryophyllene oxide. (C) 2018 ACG Publications. All rights reserved.

\section{Introduction}

According to recent taxonomic revisions the genus Salvia is represented by 100 species in Turkey and 59 taxa are endemic [1-4]. Species of the genus are commonly used for rheumatism, warts, wounds, common cold, abdominal pain, flatulence, tonsillitis, stomachache and as antiseptic, stimulant, diuretic, laxative, antipyretic in traditional medicines [5-10]. The species have also economic value for local people;

\footnotetext{
* Corresponding author: E-Mail: burcusn@gmail.com; Phone:+90-2124400000/13582 Fax: +90-2124400252
}

The article was published by ACG Publications http://www.acgpubs.org/journal/records-of-natural-products (C) January-February 2019 EISSN:1307-6167 DOI: $\underline{\text { http://doi.org/10.25135/rnp.68.18.02.090 }}$ 
they collect the plants from nature and sell on local markets. It is commonly known as adaçayı, çalba, şalba, dağçayı in Turkish [11-12].

The studies on Salvia species exhibit the diterpene content and a number of biological activities such as antiseptic, antibacterial, astringent, anti-inflammatory, antiviral, cytotoxic, cardiovascular, sedative, tranquilizing, spasmolitic, anticonvulsant and carminative [13].

Salvia cassia Sam. ex Rech.f. is restricted to Amanos Mountains and the eastern Mediterranean region of Turkey and conservation status is "Endangered" [14]. There is an investigation on the ethanol extract of $S$. cassia (aerial parts). Its cytotoxicity against the human ovarian cancer cell line was compared with other 15 Salvia species and this extract showed a cytotoxicity with the $\mathrm{IC}_{50}$ value $29.4 \mu \mathrm{g} / \mathrm{mL}$, while the extract of $S$. hypargeia exhibited highest cytotoxicity [13].

In spite of a number of studies on Salvia species, the previous pharmacognostical studies on Salvia cassia are quite few. Therefore, this study was conducted on the antibacterial, antimycobacterial and antifungal activities of various extracts (petroleum ether $(\mathrm{PE})$, chloroform $\left(\mathrm{CHCl}_{3}\right)$ and ethanol $(\mathrm{EtOH})$ extracts; infusion and decoction) and essential oil (EO) from the aerial parts of $S$. cassia and the chemical composition of the most active sample -its EO.

\section{Materials and Methods}

\subsection{Plant Materials}

Plant materials were collected from Hatay - Kırıkhan (South Turkey) in May 2015 within the scope of the Tubitak project (No: 114S734). Voucher specimen is kept in Herbarium of Faculty of Pharmacy, Istanbul University (ISTE 107532).

\subsection{Preparation of Extracts and Essential Oil}

The dried and powdered aerial parts (AP) of Salvia cassia $(200 \mathrm{~g})$ was extracted in a Soxhlet with petroleum ether (PE extracts), chloroform $\left(\mathrm{CHCl}_{3}\right.$ extracts), ethanol (EtOH extracts) and were concentrated. An infusion and a decoction were prepared from two other portions ( $5 \mathrm{~g}$ for each preparation) with water and lyophilized. The extracts were stored at $\pm 4{ }^{\circ} \mathrm{C}$ after preparation. For isolation of essential oil (EO), the dried and powdered aerial parts $(600 \mathrm{~g})$ of Salvia cassia was hydro-distillated for $3 \mathrm{~h}$ using a Clevenger type apparatus.

The yields of $\mathrm{PE}, \mathrm{CHCl}_{3}$ and $\mathrm{EtOH}$ extracts, infusion, decoction and $\mathrm{EO}$ were found to be 0.91 , $1.14,6.79,8.39,8.09$ and $0.083 \%$ (w/w for all extracts except EO; $\mathrm{v} / \mathrm{w}$ for EO), respectively.

\subsection{Analysis of Essential Oil}

\subsubsection{GC-MS Analysis}

The GC-MS analysis was carried out with an Agilent 5975 GC-MSD system. Innowax FSC column (60 m x $0.25 \mathrm{~mm}, 0.25 \mathrm{~mm}$ film thickness) was used with helium as carrier gas $(0.8 \mathrm{~mL} / \mathrm{min})$. GC oven temperature was kept at $60^{\circ} \mathrm{C}$ for $10 \mathrm{~min}$ and programmed to $220^{\circ} \mathrm{C}$ at a rate of $4^{\circ} \mathrm{C} / \mathrm{min}$ that was kept constant at $220^{\circ} \mathrm{C}$ for $10 \mathrm{~min}$ and followed by elevating the temperature to $240^{\circ} \mathrm{C}$ at a rate of $1{ }^{\circ} \mathrm{C} / \mathrm{min}$. Split ratio was adjusted at $40: 1$. The injector temperature was set at $250^{\circ} \mathrm{C}$. Mass spectra were recorded at $70 \mathrm{eV}$. Mass range was $m / z 35$ to 450 .

\subsubsection{GC-FID Analysis}

The GC analysis was carried out using an Agilent $6890 \mathrm{~N}$ GC system. FID detector temperature was $300^{\circ} \mathrm{C}$. To obtain the same elution order with GC-MS, simultaneous auto-injection was done on a duplicate of the same column applying the same operational conditions. Relative percentage amounts of the separated compounds were calculated from FID chromatograms. 


\subsubsection{Identification of Components}

Identification of the essential oil components were carried out by comparison of their relative retention times with those of authentic samples or by comparison of their relative retention index (RRI) to series of $n$-alkanes. Computer matching against commercial (Wiley GC/MS Library, MassFinder 3 Library) $[15,16]$ and in-house "Baser Library of Essential Oil Constituents" built up by genuine compounds and components of known oils. Additionally, MS literature data $[17,18]$ was also used for the identification. A C9-C30 $n$-alkane standard solution was used for the calculation of retention indices.

\subsection{Biological Assays}

\subsubsection{Antibacterial Assay}

The antibacterial activity was evaluated in comparison against Gram positive and Gram negative reference standard microorganisms; Staphylococcus aureus ATCC 25923, methicillin resistant Staphylococcus aureus ATCC 43300 (MRSA), Entercoccus faecalis ATCC 29212, Bacillus subtilis ATCC 6633, Klebsiella pneumoniae ATCC 4352, Pseudomonas aeruginosa ATCC 27853, Proteus mirabilis ATCC 7002 and Escherichia coli ATCC 25922) from the Institute of Microorganisms Culture Collection of Istanbul Medical Faculty/Istanbul/Turkey. Ciprofloxacin (Bayer Türk Kimya San. Istanbul/Turkey) and dimethylsulfoxide (DMSO-Merck) were purchased. Tryptic soy agar (TSA) from GBL, Istanbul/Turkey, Mueller Hinton Broth (MHB) TitanBiotek, Istanbul/Turkey and Sabouraud dextrose agar were obtained from GBL Istanbul/Turkey.

The extracts were dissolved in DMSO as a concentration of $10000 \mu \mathrm{g} / \mathrm{ml}$. The antibacterial activity of the extracts was evaluated using a standard microbroth dilution and disk diffusion methods regarding Clinical Laboratory Standards Institute $[19,20]$ under Laminar Air Flow (aseptic conditions). Minimum inhibition concentration (MIC) and minimum bactericidal concentrations (MBCs) were determined for each. The positive control was taken ciprofloxacin for antibacterial activity and the DMSO was taken as vehicle control to determine the possible inhibitory activity of the diluting of extract.

\subsubsection{Minimum Inhibitory Concentration (MIC) and Minimum Bactericidal Concentration $(M B C)$}

Bacterial inoculums were prepared from overnight grown cultures $\left(24\right.$ hours at $\left.37^{\circ} \mathrm{C}\right)$ in Mueller Hinton Broth and the turbidity was adjusted equivalent to 0.5 McFarland units approximately $10^{8} \mathrm{CFU} / \mathrm{mL}$ using spectrophotometer (Multiscan Go) at $450 \mathrm{~nm}$ and diluted $1 / 100$ to the final concentration $10^{6}$ $\mathrm{CFU} / \mathrm{mL}$ for each bacteria.

The MIC and MBC values of extracts were determined based on a microbroth dilution method in 96 multi-well microtitre plates. The $50 \mu \mathrm{g} / \mathrm{mL}$ MHB were added to the wells starting from the second until the 12th. The crude plant extracts of $10000 \mu \mathrm{g} / \mathrm{mL}$ were added to the first and second wells. Two-fold dilutions were made down to the desired minimum concentration starting from the highest concentration $10000 \mu \mathrm{g} / \mathrm{mL}$ in the first well, continuing with the second well which includes $5000 \mu \mathrm{g} / \mathrm{mL}$ down to the lowest concentration $19.52 \mu \mathrm{g} / \mathrm{mL}$ in the tenth well. Finally, $25 \mu \mathrm{L}$ of bacterial suspensions and $0.001 \%$ resazurin solution were added to each well, except the last well and the range of $5000-9.76 \mu \mathrm{g} / \mathrm{mL}$ were achieved.

In each plate, one row with a broad-spectrum antibiotic was used as the positive control (ciprofloxacin in serial dilution 32 to $0,03 \mu \mathrm{g} / \mathrm{mL}$ ). An additional row of DMSO was used as vehicle control to determine possible inhibitory activity of the dilutant of extract.

After incubation, at $37^{\circ} \mathrm{C}$ for 24 hours, the microtitre plates were examined visually for microbial growth which appeared as pink colored by resazurin dye. In each row, the well containing the least concentration and showed no visible growth was considered the MIC. To determine the MBC in each tested row in the MIC determination, a broth sample was collected from the wells which did not show visible growth and the samples were inoculated on TSA plates at $37^{\circ} \mathrm{C}$ for 24 hours. MBC's were determined with samples which did not show any growth. 


\subsubsection{Antimycobacterial Assay}

Microdilution method was used according to a standard protocol by Clinical and Laboratory Standard Institute (CLSI) [21,22]. Three strains were tested including each of the following species: M. tuberculosis H37Rv ATCC 27294 (Susceptible all antimycobacterial drugs, American Type Culture Collection, USA), M. tuberculosis H37Rv ATCC 35838 (resistant to Rifampicin (R), American Type Culture Collection, USA) and multi-drug resistant (resistant to Isoniazid + Rifampicin (INH+R)) M. tuberculosis that was isolated from patient by Istanbul Faculty of Medicine, Department of Microbiology Laboratory.

Middlebrook 7H9 broth medium (Becton and Dickinson, USA) was used for microdilution method. The medium was adjusted to $\mathrm{pH} 7.0$ at $25^{\circ} \mathrm{C}$. Sterility control of each bottle was performed before it was used.

Rifampicin was provided by the Becton Dickinson (BD, USA) as standard lyophilized powders and dissolved in sterile distilled water. The extracts were dissolved in $100 \%$ dimethyl sulfoxide, EO were dissolved in Middlebrook 7H9 with 5\% Tween80 [23] according to CLSI methods [21,22]. The final concentrations were 400 to $3,125 \mu \mathrm{g} / \mathrm{mL}$, and 50 to $0.1 \mu \mathrm{L} / \mathrm{mL}$ for extracts and EO respectively. The critical concentration $(1 \mu \mathrm{g} / \mathrm{mL})$ was used for rifampicin.

Preparation of inoculum suspensions of mycobacteria were based mainly according to the CLSI guidelines [21] and described previously [23]. The isolates were subcultured on to Löwenstein Jensen medium at $37^{\circ} \mathrm{C}$, during 20-25 days. A few colonies from freshly grown $M$. tuberculosis were suspended in Middlebrook $7 \mathrm{H} 9$ broth medium to obtain 1.0 McFarland turbidity and then it was diluted ten times using the same medium.

The broth microdilution test was performed by using sterile, disposable microdilution plates (96 Ushaped wells from LP Italiano SPA, Milano, Italy). Rows from 1 to 11 contained the series of drug dilutions in $100 \mu \mathrm{L}$ volumes and last row (number 12) contained $100 \mu \mathrm{L}$ of drug-free medium, which served as the growth control. Each well was inoculated on the day of the test with $100 \mu \mathrm{L}$ of the corresponding inoculum. This step brought the drug dilutions and inoculum size to the final test concentrations given above.

The microplates which contained including M. tuberculosis were incubated at $37^{\circ} \mathrm{C}$ until mycobacterial growth was clearly observed in positive control row as white sediment. Mycobacterial growth was confirmed by Ehrlich-Ziehl-Neelsen acid fast stain. For all drugs, the minimal inhibitory concentrations (MICs) was defined as the lowest concentration of the drug which resulted in a complete inhibition of visible growth compared to that one of drug-free growth control (100\% inhibition) [21].

\subsubsection{Antifungal Assay}

Microdilution method was used according to a standard protocol by CLSI [24-26]. Five strains were tested each of the following species: C. albicans ATCC 90028 (American Type Culture Collection, USA), Candida parapsilosis ATCC 22019 (American Type Culture Collection, USA), C. krusei ATCC 6258 (American Type Culture Collection, USA), Trichophyton mentagrophytes var. erinacei NCPF 275 (National Collection of Pathogenic Fungi, Public Health England), Microsporum gypseum NCPF-580 (National Collection of Pathogenic Fungi, Public Health England).

RPMI 1640 broth with L-glutamine without sodium bicarbonate and $0.165 \mathrm{M}$ MOPS buffer $(34.54 \mathrm{~g} / \mathrm{L})$ was used. The medium was adjusted to $\mathrm{pH} 7.0$ at $25^{\circ} \mathrm{C}$. Sterility control of each bottle was performed before it was used.

Amphotericin B was provided by the Sigma (Catalog number: A4888) as standard powder and itraconazole was provided by Johnson \& Johnson (Johnson \& Johnson Sihhi Malzeme San. ve Tic. Ltd. Şti. Istanbul, Turkey). Amphotericin B, itraconazol and the extracts were dissolved in $100 \%$ dimethyl sulfoxide and EO was dissolved in RPMI 1640 with 5\% Tween80 [27] recommended as CLSI guidelines [24-26]. The final concentrations extracts were 400 to $3.13 \mu \mathrm{g} / \mathrm{mL}$, amphotericin B and itraconazol were 64 to $0.03 \mu \mathrm{L} / \mathrm{mL}$, for aqueous EO's were 50 to $0.1 \mu \mathrm{L} / \mathrm{mL}$.

Preparation of inoculum suspensions of dermatophytes was based according to the CLSI guidelines [24] and described previously [28]. The isolates were subcultured on to potato dextrose agar (PDA) plates at $30^{\circ} \mathrm{C}$ during $4-5$ days. The fungal colonies were covered with $1 \mathrm{~mL}$ of sterile $0.85 \%$ saline and suspensions were made by gently probing the surface with the tip of Pasteur pipette. The resulting mixture 
of conidia and hyphal fragments was withdrawn and transferred to a sterile tube. Heavy particles were allowed to settle for 5-10 min at room temperature; the upper suspension was mixed with a vortex for 15 sec. The turbidity of supernatants was measured spectrophotometrically (Pharmacia, LKB. Ultrospec II) at a wavelength of $530 \mathrm{~nm}$, and transmission was adjusted to 65 to $75 \%$. These stock suspensions were diluted 1:50 in RPMI medium to obtain the final inoculum sizes, which range from $1 \times 10^{3}$ to $3 \times 10^{3}$ $\mathrm{CFU} / \mathrm{mL}$. For dermatophytes; a constant volume $(100 \mu \mathrm{L})$ of the inoculum was added to each microdilution well containing $100 \mu \mathrm{L}$ of the serial dilution of drugs to reach final concentrations. The microplates which contained dermatophytes were incubated at $28^{\circ} \mathrm{C}$ during 7 days. The microplates were read visually with the aid to an inverted reading mirror after 7 days for dermatophytes. For all drugs except itraconazole $(80 \%$ inhibition), the MICs were defined as the lowest concentration of the drug (100\% inhibition) which resulted in a complete inhibition of visible growth compared to that one of drug-free growth control [24].

Preparation of inoculum suspensions of yeasts were based mainly on the CLSI guidelines [25,26]. The colonies of yeasts after $48 \mathrm{~h}$ at $35^{\circ} \mathrm{C}$ of incubation onto Sabouraud dextrose agar (BBL, Sparks, MD, USA) was subcultured to $5 \mathrm{~mL}$ sterile saline $(0.85 \%)$ and turbidity was adjusted spectrophotometrically at $530 \mathrm{~nm} \mathrm{0.5} \mathrm{Mc} \mathrm{Farland} \mathrm{Standard,} \mathrm{and} \mathrm{firstly} \mathrm{it} \mathrm{was} \mathrm{diluted} \mathrm{1:50} \mathrm{and} \mathrm{then} \mathrm{1:20} \mathrm{in} \mathrm{RPMI} 1640$ in order to obtain a final concentration of $0.5 \times 10^{3}$ to $2.5 \times 10^{3} \mathrm{CFU} / \mathrm{mL}$.

The broth microdilution test was performed by using sterile, disposable microdilution plates (96 Ushaped wells from LP Italiano SPA, Milano, Italy). Rows from 1 to 11 contained the series of drug dilutions in $100 \mu \mathrm{L}$ volumes and last row (row 12) contained $100 \mu \mathrm{L}$ of drug-free medium, which served as the growth control. Each well was inoculated on the day of the test with $100 \mu \mathrm{L}$ of the corresponding inoculum. This step brought the drug dilutions and inoculum size to the final test concentrations given above. For yeasts; a constant volume $(100 \mu \mathrm{L})$ of the inoculum was added to each microdilution well containing $100 \mu \mathrm{L}$ of the serial dilution of drugs to reach final concentrations. The microplates were incubated at $35^{\circ} \mathrm{C}$ for $48 \mathrm{~h}$. For all drugs MICs except itraconazole ( $80 \%$ inhibition) were defined as the lowest concentration showing $100 \%$ inhibition of growth $[25,26,29]$.

\section{Results and Discussion}

\subsection{Antibacterial Activity Assay}

Table 1. The results of the antibacterial tests.

\begin{tabular}{|c|c|c|c|c|c|c|c|c|}
\hline \multicolumn{9}{|c|}{ MICs /MBCs $(\mu \mathrm{g} / \mathrm{mL})$} \\
\hline & S.a. & MRSA & $E . f$. & B.s. & K.p. & P.a. & P.m. & E.c. \\
\hline PE extract & $\begin{array}{l}625 / \\
1250\end{array}$ & 1250 & 1250 & $625 / 1250$ & 1250 & 1250 & 1250 & 1250 \\
\hline $\mathrm{CHCl}_{3}$ extract & $\begin{array}{l}625 / \\
1250\end{array}$ & $\begin{array}{c}625 / 125 \\
0\end{array}$ & 1250 & $625 / 1250$ & 1250 & 1250 & 1250 & 1250 \\
\hline EtOH extract & $\begin{array}{l}625 / \\
2500\end{array}$ & 1250 & 1250 & $625 / 1250$ & 1250 & $\begin{array}{l}625 / \\
2500\end{array}$ & 1250 & 1250 \\
\hline Infusion & $>5000$ & $>5000$ & $>5000$ & $>5000$ & $>5000$ & $>5000$ & $>5000$ & $>5000$ \\
\hline Decoction & 2500 & $>5000$ & $>5000$ & $>5000$ & $>5000$ & $\begin{array}{c}2500 / 50 \\
00\end{array}$ & $>5000$ & $>5000$ \\
\hline Ciprofloxacin & 0.5 & 0.5 & 0.5 & 0.25 & 0.5 & 0.25 & 0.25 & 0.06 \\
\hline DMSO & $\begin{array}{c}1250 / 25 \\
00\end{array}$ & 2500 & 1250 & $2500 / 5000$ & 1250 & 1250 & 1250 & $1250 / 2500$ \\
\hline \multicolumn{9}{|c|}{ MICs /MBCs $(\mu \mathrm{L} / \mathrm{mL})$} \\
\hline EO & $0.6 / 1.25$ & $0.6 / 1.25$ & $\begin{array}{c}0.6 / 2 \\
5\end{array}$ & $0.3 / 2.5 \quad 1$ & $25 / 2.5$ & $0.6 / 1.25$ & $1.25 / 2.5$ & 1.25 \\
\hline
\end{tabular}


The antimicrobial activities of all samples were summarized by micro dilution method and disc diffusion method (Table 1). The tests were performed in duplicate and the results were signified as average values.

The EO showed more activity among all samples and it has weak activity against $S$. aureus, MRSA, E. faecalis, $P$. aeruginosa; and it has stronger activity against $B$. subtilis.

\subsection{Antimycobacterial Assay}

The results of antimycobacterial tests can be seen in the Table 2. In antimycobacterial activity analysis, the results of EO are very remarkable. It had stronger activity even against the multidrug resistant isolated strains. Also, it showed good activity against the other strains - susceptible; resistant to isoniazid and to rifampicin, too.

Table 2. The results of the antimycobacterial tests.

\begin{tabular}{lccccc}
\hline & \multicolumn{5}{c}{ MICs $(\boldsymbol{\mu g} / \mathbf{m L})$} \\
& $\mathbf{A}$ & $\mathbf{B}$ & $\mathbf{C}$ & $\mathbf{D}$ & $\mathbf{E}$ \\
\hline PE extract & 50 & 100 & 100 & 100 & 100 \\
$\mathrm{CHCl}_{3}$ extract & 100 & 200 & 200 & 50 & 200 \\
EtOH extract & 400 & 400 & 400 & 400 & 400 \\
Infusion & 400 & 400 & 400 & 400 & 400 \\
Decoction & 400 & 400 & 400 & 400 & 400 \\
Rifampicin & $<1$ & $<1$ & $>1$ & $>1$ & $>1$ \\
Isoniazid & $<0.1$ & $>0.1$ & $<0.1$ & $>0.1$ & $>0.1$ \\
\hline \multicolumn{7}{c}{ MICs $(\boldsymbol{\mu L} / \mathbf{m L})$} \\
\hline EO & 0.4 & 0.4 & 0.2 & 0.8 \\
\hline
\end{tabular}

A: M. tuberculosis H37Rv ATCC 27294 (susceptible all antimycobacterial drugs); B: M. tuberculosis H37Rv ATCC 35822 (resistant to isoniazid); C: M. tuberculosis H37Rv ATCC 35838 (resistant to rifampicin); D: Multi-drug resistant M. tuberculosis (resistant to isoniazid and rifampicin - isolated from patient); E: Multi-drug resistant M. tuberculosis (resistant to streptomycin + isoniazid + rifampicin + ethambutol - isolated from patient) PE: Petroleum ether

\subsection{Antifungal Assay}

Table 3. The results of the antifungal tests.

\begin{tabular}{lccccc}
\hline & F & G & MICs $(\boldsymbol{\mu g} / \mathbf{m L})$ & $\mathbf{I}$ & J \\
\hline PE extract & 100 & 100 & 100 & 50 & 100 \\
$\mathrm{CHCl}_{3}$ extract & 50 & 50 & 100 & 100 & 50 \\
EtOH extract & 200 & 200 & 400 & 100 & 200 \\
Infusion & 200 & 200 & 400 & 200 & 100 \\
Decoction & 200 & 200 & 400 & 200 & 200 \\
Amphotericin B & 0.5 & 0.5 & 4 & 2 & 1 \\
(100\% inhibition) & & & & & \\
Itraconazol & 0.06 & 0.12 & 0.5 & 0.5 & 0.5 \\
$(80 \%$ inhibition) & & & & & \\
\hline
\end{tabular}

\begin{tabular}{lccccc}
\hline \multicolumn{7}{c}{ MICs $(\mu \mathbf{L} / \mathbf{m L})$} \\
\hline EO & 0.2 & 0.1 & 6.25 & 0.1 & 0.1 \\
\hline
\end{tabular}

F: Candida albicans ATCC 90028; G: Candida parapsilosis ATCC 22019; H: Candida krusei ATCC 6258;

I: Trichophyton mentagrophytes var. erinacei NCPF 275; J: Microsporum gypseum NCPF 580. 
Similar results were obtained in antifungal tests (Table 3). The most active sample was EO. While it exhibited good activity against all Candida species, it had very good effect against dermatophytes with the MICs $0.1 \mu \mathrm{L} / \mathrm{mL}$.

\subsection{Isolation of the Essential Oil}

As a result of all data, it can be seen that the EO was much more active than other samples, even than the standards. Thus, the study was continued with the determination of EO's chemical composition. The data and the chromatogram of the EO are seen in Figure S1 and Table 4. The major component group is oxygenated sesquiterpenes.

The plant kingdom provide over 100.000 secondary metabolites and the medicinal plants have an important place in the treatment of different diseases, also infectious diseases. Most of the compounds, isolated from natural sources, are determined as antimicrobial agents and some of them are the first step in drug discovery [33].

In a study, given the results in antimicrobial tests of EO from Salvia tomentosa Mill.. It exhibited an inhibition on the growth of Staphylococcus aureus, Staphylococcus epidermidis, Escherichia coli, Enterococcus faecalis and Enterobacter cloacae [34]. Beside of this, the essential oil of Salvia heldreichiana Boiss. ex Benth. showed an activity on the growth of E. coli, Salmonella typhimurium and Sarcina lutea, while the EO of Salvia cryptantha Montbret et Aucher ex Bentham inhibited the growth of S. lutea [35]. In an other investigation, the reseachers demonstrated that the EOs of Salvia multicaulis Vahl, S. palaestina Benth., S. syriaca L. and S. ceratophylla L. showed a good effect on some bacteria such as $S$. aureus, E. coli and Bacillus subtilis; in addition, the EO of $S$. multicaulis exhibited an activity against Pseudomonas aeruginosa and the EO of $S$. syriaca against $P$. aeruginosa and Streptococcus pyogenes [36].

Beside of the studies on EO from Salvia species, the investigations on the antibacterial activity of their extracts in literature, too. For example, the methanol extract, gained from Salvia libanotica Labill., was found active against a clinical isolate of methicillin-resistant by the turkish reseachers [37].

The treatments of the tuberculosis and fungal diseases take a long time. Meanwhile, a resistance can develop against the known therapeutic agents or some toxicity problems can consist. Hereby, the treatment will not be useful. Because of the necessity of new therapeutic agents, the investigations for this aim increase day by day.

In a study in Turkey, the EOs from the aerial parts of five Salvia tomentosa, S. aucheri Benth., $S$. fruticosa Mill., S. aramiensis Rech.f. and S. verticillata L. subsp. amasiaca Freyn \& Bornm. in Turkey showed an antimycobacterial activities [38,39].

16 Salvia species, preferred traditionally in South Africa against various infections, were investigated for their antibacterial and antimycobacterial activities and it is determined that three Salvia species $(S$. verbenaca L., S. radula Benth. and S. dolomitica Codd) had a remarkably effect on M. tuberculosis (MIC < $0.50 \mathrm{mg} / \mathrm{mL}$ ) [40].

The antifungal activities of the extracts and EOs, prepared from Salvia officinalis L., S. fruticosa Miller and S. tomentosa were demonstrated with the previous studies [41-48].

Badiee et al. [23] compared the EO of S. officinalis and some antifungal agents for their antifungal effects on C. parapsilosis, C. krusei, C. albicans and C. glabrata and proposed that $S$. officinalis is as a natural antifungal agent. Furthermore, the EO from $S$. sclarea L. and the compounds, isolated from EO, (linalyl acetate and linalool), were studied against 30 different yeasts. The essential oil had stronger effect than the compounds [49]. Also, the antifungal activity of $S$. officinalis against yeasts, filamentous fungi was determined by macrodilution broth method. It showed an antifungal activity with the MIC values of 1.25$10 \mu \mathrm{L} / \mathrm{mL}$; and against dermatophytes with MIC values of $0.63-2.5 \mu \mathrm{L} / \mathrm{mL}$ [46]. Additionally, its decoction, infusion and polar extract (prepared with methanol: water (80:20)) found effective on some Candida species as well as $C$. parapsilosis, by disc diffusion method [48]. In a study on the antifungal effect of the extracts, extracted with ethanol from the different parts of Salvia tigrina Hedge \& Hub. Mor., all of them exhibited an effect, especially on C. neoformans, C. albicans and Botrytis cinarea [27]. The effects of the EO and the different extracts of $S$. tomentosa on C. albicans and C. krusei were determined [41]. Similar studies and data can be found on S. fruticosa in literature, too [42]. However, the antimycobacterial and antifungal activities of $S$. cassia has not been determined before. 
Table 4. Composition of essential oil (EO).

\begin{tabular}{|c|c|c|c|c|}
\hline $\mathbf{K I}^{\mathbf{a}}$ & $\mathbf{R R I}^{\mathbf{b}}$ & Compound & $\%^{c}$ & $\mathbf{I M}^{\mathrm{d}}$ \\
\hline $1025^{\mathrm{e}}$ & 1032 & $\alpha$-Pinene & 0.1 & $\mathrm{tR}, \mathrm{MS}$ \\
\hline $1122^{\mathrm{e}}$ & 1132 & Sabinene & 0.1 & $\mathrm{tR}, \mathrm{MS}$ \\
\hline $1245^{\mathrm{e}}$ & 1255 & $\gamma$-Terpinene & 1.2 & $\mathrm{tR}, \mathrm{MS}$ \\
\hline $1282^{\mathrm{e}}$ & 1280 & $p$-Cymene & 3.1 & $\mathrm{tR}, \mathrm{MS}$ \\
\hline $1480^{\mathrm{e}}$ & 1466 & $\alpha$-Cubebene & 0.1 & MS \\
\hline \multirow[t]{2}{*}{$1488^{\mathrm{e}}$} & 1497 & $\alpha$-Copaene & 1.2 & MS \\
\hline & 1515 & Theaspirane A & 0.1 & MS \\
\hline $1523^{\mathrm{e}}$ & 1535 & $\beta$-Bourbonene & 0.8 & MS \\
\hline \multirow[t]{2}{*}{$1541^{\mathrm{f}}$} & 1549 & $\beta$-Cubebene & 0.1 & MS \\
\hline & 1556 & Theaspirane B & 0.3 & MS \\
\hline $1588^{\mathrm{f}}$ & 1589 & Isocaryophyllene & 1.0 & MS \\
\hline $1590^{\mathrm{f}}$ & 1600 & $\beta$-Elemene & 0.2 & $\mathrm{tR}, \mathrm{MS}$ \\
\hline $1601^{\mathrm{f}}$ & 1611 & Terpinen-4-ol & 0.2 & $\mathrm{tR}, \mathrm{MS}$ \\
\hline $1608^{\mathrm{e}}$ & 1612 & $\beta$-Caryophyllene & 6.0 & $\mathrm{tR}, \mathrm{MS}$ \\
\hline $1658^{g}$ & 1658 & Sabinyl acetate & 2.1 & MS \\
\hline $1663^{e}$ & 1687 & $\alpha$-Humulene & $\mathrm{t}$ & $\mathrm{tR}, \mathrm{MS}$ \\
\hline $1689^{\mathrm{e}}$ & 1704 & $\gamma$-Muurolene & $\mathrm{t}$ & MS \\
\hline $1708^{\mathrm{e}}$ & 1726 & Germacrene D & 4.6 & $\mathrm{tR}, \mathrm{MS}$ \\
\hline $1723^{\mathrm{e}}$ & 1740 & $\alpha$-Muurolene & $\operatorname{tr}$ & MS \\
\hline $1755^{\mathrm{e}}$ & 1773 & $\delta$-Cadinene & 0.3 & MS \\
\hline $1820^{\mathrm{f}}$ & 1838 & $(E)$ - $\beta$-Damascenone & 0.2 & MS \\
\hline $1945^{\mathrm{g}}$ & 1945 & 1,5-Epoxy-salvial(4)14-ene & 2.4 & MS \\
\hline $2001^{g}$ & 2001 & Isocaryophyllene oxide & 1.1 & MS \\
\hline $1986^{\mathrm{e}}$ & 2008 & Caryophyllene oxide & 22.3 & $\mathrm{tR}, \mathrm{MS}$ \\
\hline $2016^{\mathrm{e}}$ & 2037 & Salvial-4(14)-en-1-one & 1.7 & MS \\
\hline $2047^{\mathrm{e}}$ & 2071 & Humulene epoxide-II & 1.1 & MS \\
\hline $2128^{\mathrm{g}}$ & 2130 & Salviadienol & 1.6 & MS \\
\hline $2124^{\mathrm{e}}$ & 2131 & Hexahydrofarnesyl acetone & 0.2 & MS \\
\hline $2126^{\mathrm{e}}$ & 2144 & Spathulenol & 3.1 & MS \\
\hline $2209^{g}$ & 2209 & T-Muurolol & 0.1 & MS \\
\hline $2227^{\mathrm{e}}$ & 2255 & $\alpha$-Cadinol & 1.0 & MS \\
\hline \multirow[t]{2}{*}{$2248^{\mathrm{g}}$} & 2278 & Torilenol & 1.4 & MS \\
\hline & 2287 & 8,13-Epoxy-15,16-dinor-labd-12-ene & 9.0 & MS \\
\hline $2289^{g}$ & 2289 & Oxo- $\alpha$-Ylangene & 1.8 & MS \\
\hline $2316^{\mathrm{g}}$ & 2316 & $\begin{array}{l}\text { Caryophylla-2(12),6(13)-dien-5 } 3 \text {-ol } \\
(=\text { Caryophylladienol I) }\end{array}$ & 1.0 & MS \\
\hline \multirow[t]{2}{*}{$2366^{\mathrm{e}}$} & 2369 & Eudesma-4(15),7-dien-1 $\beta$-ol & 0.6 & MS \\
\hline & 2373 & 14-Oxo- $\alpha$-muurolene & 0.5 & MS \\
\hline \multirow[t]{2}{*}{$2392^{f}$} & 2392 & Caryophylla-2(12),6-dien-5 $\beta$-ol (=Caryophyllenol II) & 3.6 & MS \\
\hline & 2396 & 13-epi-Manoyl oxide ( $=8 \alpha-13$-oxy-14-en-epilabdane $)$ & 3.1 & MS \\
\hline $2535^{\mathrm{g}}$ & 2568 & 14-Hydroxy- $\alpha$-muurolene & 0.2 & MS \\
\hline $2607^{\mathrm{g}}$ & 2607 & 14 -Hydroxy- $\delta$-cadinene & 0.3 & MS \\
\hline $2613^{\mathrm{f}}$ & 2622 & Phytol & 0.2 & MS \\
\hline $2686^{\mathrm{f}}$ & 2670 & Tetradecanoic acid & 1.2 & $\mathrm{tR}, \mathrm{MS}$ \\
\hline \multirow[t]{2}{*}{$2687^{\mathrm{f}}$} & 2679 & Manool & 2.1 & MS \\
\hline & 2735 & Labda-7,14 dien-13-ol & 1.6 & MS \\
\hline \multirow[t]{8}{*}{$2913^{\mathrm{e}}$} & 2931 & Hexadecanoic acid & 5.7 & $\mathrm{tR}, \mathrm{MS}$ \\
\hline & & Monoterpene Hydrocarbons & 4.5 & \\
\hline & & Oxygenated Monoterpenes & 2.3 & \\
\hline & & Sesquiterpene Hydrocarbons & 14.3 & \\
\hline & & Oxygenated Sesquiterpenes & 43.8 & \\
\hline & & Fatty acids & 6.9 & \\
\hline & & Diterpenes & 16.0 & \\
\hline & & Others & 0.8 & \\
\hline
\end{tabular}

${ }^{\mathrm{a} K I}$ Kovats indices from literature e) [30], f) [31], g) [32]; bRI: Relative retention indices calculated against $n$-alkanes; ${ }^{\mathrm{c}} \%$ : calculated from FID data; ${ }^{\mathrm{d}} \mathrm{IM}$ : Identification Method; tR, identification based on the retention times (tR) of genuine standard compounds on the HP Innowax column; MS, tentatively identified on the basis of computer matching of the mass spectra with those of the Wiley and MassFinder libraries and comparison with literature data; $\mathrm{t}$ : Trace $(<0.1 \%)$. 
The investigations on the effects of the isolated compounds can be found in literature and are very notable to designate and evaluate the effectiveness of the plants [50,51]. As an example for these investigation, an in vitro study can be given, in which the usage of caryophyllene oxide (as antifungal activity) in an experimental model of onychomycosis was designated and a comparison between caryophyllene oxide, sulconazole and ciclopiroxolamine, two agents in the treatment of onychomycosis. In this study, the antifungal activity of caryophyllene oxide against dermatophytes was mentioned, too [52]. Also, on the effects of the isolated compounds, $\alpha$-thujone, 1,8 -cineole, $\beta$-thujone, camphor, linalool, linalyl acetate exhibited good activity against yeasts [43]. In addition, linalool and linalyl acetate have showed high effect on various Candida species (C. albicans, Candida krusei, Candida parapsilosis, etc.) [40,49]. Furthermore, two constituents from EO -camphor and 1,8-cineole- are distinguished chemicals having antimicrobial potentials $[53,54]$.

In summary, the EO of Salvia cassia was most active sample in all activity tests, especially against Bacillus subtilis; M. tuberculosis strains -resistant to rifampicin and multidrug resistant-; also two dermatophytes (Trichophyton mentagrophytes var. erinacei and Microsporum gypseum). Therefore, the EO was investigated for its composition.

By GC-FID and GC-MS analysis of the EO of $S$. cassia, a species, belonging to the section of Aethiopis, the major compound was found caryophyllene oxide, followed by other compounds $(8,13$ epoxy-15,16-dinor-labd-12-ene, $\beta$-caryophyllene, hexadecanoic acid and germacrene D) [55,56]. Three species (Salvia spinosa L., S. macrosiphon Boiss. and S. atropatana Bunge) among 34 species in the section of Aethiopis, exhibited very different yields of caryophyllene oxide from each other in the studies on the samples collected from various localities. While the yield of caryophyllene oxide was $63 \%$ in the essential oil of S. spinosa collected from Iran, it was determined $0.1 \%$ in the samples from Jordan; also $26.9 \%, 19.3 \%, 11.3 \%$ and $0.7 \%$ in the essential oil of $S$. macrosiphon collected from four different localities in Iran; in the essential oil of S. atropatana 19.3\% from Tehran, 0.7\% from Fars province (Shiraz) in Iran [57-62]. According to the data in studies on the species, S. cassia has the highest amount of caryophyllene oxide $(22.3 \%)$ after these species on the fourth place among the species in the section of Aethiopis. S. frigida, S. cilicica and S. hypargeia are other species, which contain caryophyllene oxide at the high yields, $19.4 \%, 14.9 \%$ and $10.7 \%$, respectively. This compound was found as major component only in S. frigida among these three species [63-65]. There are also the species in the section of Aethiopis, in which caryophyllene oxide was determined. In the light of the studies in literature, some of these species and their content of caryophyllene oxide: Salvia vermifolia Hedge \& Hub.-Mor. (8.69\%), S. microstegia Boiss. \& Balansa (6.2\%), S. modesta Boiss. (5.31\%), S. aethiopis L. (0.5-5\%), S. argentea L. (3.28-4.11\%), S. chionantha Boiss. (3.89\%), S. syriaca L. (0.43-3\%), S. indica L. (2\%), S. sclarea L. (0.27-2.34\%), S. chrysophylla Stapf (0.98\%) and S. limbata C. A. Mey. (0.4\%) [57, 61, 66-79].

As mentioned in "Flora of Turkey and the East Aegean Islands, VII", S. cassia is closely related to $S$. cilicica. As a matter of fact, S. cilicica contains a good ratio of caryophyllene oxide (14.9\%). 8,13-epoxy15,16-dinor-labd-12-ene, which is other major component in the essential oil of $S$. cassia $(9 \%)$, was also found in S. cilicica (1.6\%). In a study on the essential oils of S. limbata from two different localities (Van and Erzurum) in Turkey, their amounts were detected $0.4 \%$ and $3.7 \%$, repectively. Additionally, this compound was determined in S. glutinosa (4.6\%) and S. sclarea (1.02-3.03\%), too. In brief, this compound was obtained from four species in the secton of Aethiopis $[2,55,64,76,79,80]$.

Among isolated compounds from $S$. cassia; caryophyllene oxide, $\beta$-caryophyllene, hexadecanoic acid and germacrene $\mathrm{D}$ were found before in the plants, which showed antimicrobial activity, for example Ballota pseudodictamnus L. Bentham, Lippia multiflora Moldenke, Origanum syriacum L., Lantana camara L. and Piper betle L.. Beside of these species, three species in Salvia genus (S. trichoclada Benth., S. multicaulis and S. frigida Boiss.), recorded with their antimicrobial activities in literature, contain caryophyllene oxide as major compounds in their essential oil, with the similar yield $(25.1 \%, 22.5 \%$, $19.4 \%$, respectively) as like as $S$. cassia $(22.3 \%)$. These support that, these compounds may have a role in studied activities. In the light of all, it gives the impression that, this plant can be used as a source with its antimycobacterial and antifungal effects, for the aim to the treatment of various fungal diseases and tuberculosis, especially multidrug resistant tuberculosis, which is today very dangerous for the human health. It will be useful to continue the investigations on Salvia species for the aim to find new therapeutic agents against resistant tuberculosis and fungal diseases [36,63,64,81-89]. 


\section{Acknowledgments}

The parts of the antibacterial and antimycobacterial assays in this present work was supported by the Scientific and Technological Research Council of Turkey. Project No. 114S734.

This study was presented in the congress "Lamiaceae 2017" with the name "Pharmacognostical investigation on Salvia cassia" and its abtract was published in Natural Volatiles \& Essential Oils [90]..

\section{Supporting Information}

Supporting information accompanies this paper on http://www.acgpubs.org/RNP

\section{ORCID}

Burcu Sen-Utsukarci: 0000-0002-2720-9686

Bahar Gürdal: 0000-0003-4009-100X

Merve Bilgin: 0000-0003-2242-8940

Dilek Satana: 0000-0002-8827-1504

Betul Demirci: 0000-0003-2343-746X

Nur Tan: 0000-0001-7958-1917

Afife Mat: $\underline{0000-0002-9225-8572}$

\section{References}

[1] F. Celep and A. Kahraman (2012). Salvia, In: Türkiye Bitkileri Listesi (Damarlı Bitkiler), A Checklist of the Flora of Turkey (Vascular Plants), ed: A. Güner, S. Aslan, T. Ekim, M. Vural and M.T. Babaç, Nezahat Gokyigit Botanik Bahcesi ve Flora Araştirmalari Dernegi Yayini, Istanbul, pp. 575-581.

[2] C. Hedge (1982). Salvia L. In: Flora of Turkey and the East Aegean Islands. Vol.7. ed: P.H. Davis, Edinburgh Univ. Press, Edinburgh, pp. 400-461.

[3] N. Özhatay, Ş. Kültür and B. Gürdal (2017). Check-list of additional taxa to the supplement flora of Turkey VIII, Istanbul J. Pharm. 47(1), 31-46.

[4] F. Celep, T. Dirmenci and O. Guner (2015). Salvia hasankeyfense (Lamiaceae), a new species from Hasankeyf (Batman, South-eastern Turkey), Phytotaxa 227:3, 289-294.

[5] T. Baytop (1999). Türkiye'de bitkiler ile tedavi. (2nd ed.). Nobel Tıp Kitapevleri Ltd. Şti. Istanbul.

[6] B. Gürdal and S. Kültür (2013). An ethnobotanical study of medicinal plants in Marmaris (Mugla, Turkey), J. Ethnopharmacol. 146, 113-126.

[7] E. Sezik, E. Yeşilada, G. Honda, Y. Takaishi, Y. Takeda and T. Tanaka (2001). Traditional medicine in Turkey X. Folk medicine in Central Anatolia, J. Ethnopharmacol. 75, 95-115.

[8] E. Sezik, E. Yeşilada, M. Tabata, G. Honda, Y. Takaishi, T. Fujita, T. Tanaka and Y. Takeda (1997). Traditional medicine in Turkey VIII. Folk Medicine in East Anatolia; Erzurum, Erzincan, Agri, Kars, Igdir provinces, Econ. Bot. 51(3), 195-211.

[9] E. Yeşilada, G. Honda, E. Sezik, M. Tabata, K. Goto and Y. Ikeshiro (1993). Traditional medicine in Turkey IV. Folk medicine in Mediterranean subdivision, J. Ethnopharmacol. 39, 31-38.

[10] T. Fujita, E. Sezik, M. Tabata, E. Yesilada, G. Honda, Y. Takeda, T. Tanaka and Y. Takaishi (1995). Traditional medicine in Turkey VII. Folk medicine in middle and west Black Sea regions, Econ. Bot. 49(4): 406-422.

[11] T. Baytop (1994). Turkce Bitki Adlari Sozlugu. Atatürk Kültür, Dil ve Tarih Yüksek Kurumu-Türk Dil Kurumu Yayınları, Ankara.

[12] E. Tuzlacı (2006). Turkiye Bitkileri Sozlugu. Alfa Yayinlari, Istanbul.

[13] G. Topcu, Z. Turkmen, J.K. Schilling, D.G.I. Kingston, J.M. Pezzuto and A. Ulubelen (2008). Cytotoxic activity of some Anatolian Salvia extracts and isolated abietane diterpenoids, Pharm. Biol. 46, 180-184.

[14] F. Celep, M. Doğan and A. Kahraman (2010). Re-evaluated conservation status of Salvia (sage) in Turkey I: The Mediterranean and the Aegean geographic regions, Turk. J. Bot. 34, 201-214.

[15] F.W. McLafferty and D.B. Stauffer (1989). The Wiley/NBS Registry of Mass Spectral Data, Wiley and Sons, New York. 
[16] W.A. Koenig, D. Joulain and D.H. Hochmuth (2004). Terpenoids and Related Constituents of Essential Oils. MassFinder 3, Hamburg, Germany.

[17] D. Joulain and W.A. Koenig (1998). The Atlas of Spectra Data of Sesquiterpene Hydrocarbons. EB-Verlag, Hamburg.

[18] ESO 2000 (1999). The Complete Database of Essential Oils, Boelens Aroma Chemical Information Service, Netherland.

[19] M07 - Methods for dilution antimicrobial susceptibility tests for bacteria (2002). Clinical and Laboratory Standards Institute, Wayne, PA.

[20] M07 - Methods for dilution antimicrobial susceptibility tests for bacteria (2006). Clinical and Laboratory Standards Institute, Wayne, PA.

[21] M24-A2 - Susceptibility testing of Mycobacteria, Nocardiae, and other aerobic Actinomycetes (2011). Approved Standard Second Edition, Clinical and Laboratory Standards Institute, Wayne, Pennsylvania, USA.

[22] D. Amsterdam (2005). Susceptibility testing of antimicrobials in liquid media. In: Antibiotics in Laboratory Medicine (5th ed.), ed: V. Lorian, Williams and Wilkins, Philadelphia, pp. 61-143.

[23] P. Badiee, A.R. Nasirzadeh and M. Motaffaf (2012). Comparison of Salvia officinalis L. essential oil and antifungal agents against Candida species, J. Pharm. Technol. Drug Res. 1, 1-5.

[24] M38-A2 - Reference method for broth dilution antifungal susceptibility testing filamentous fungi (2008). Approved Standard Second Edition. Clinical and Laboratory Standards Institute, Wayne, Pennsylvania.

[25] M27-A3 - Reference method for broth dilution antifungal susceptibility testing of yeasts (2008). Approved Standard Third Edition. Clinical and Laboratory Standards Institute, Wayne, Pennsylvania.

[26] M27-S3 - Reference method for broth dilution antifungal susceptibility testing of yeasts (2008). Approved Standard- Third Edition. Clinical and Laboratory Standards Institute, Wayne, Pennsylvania.

[27] B. Dulger and N. Hacioglu (2008). Antifungal activity of endemic Salvia tigrina in Turkey, Trop. J. Pharmaceut. Res. 7, 1051-1054.

[28] B. Fernandez-Torres, F.J. Cabanes, A. Carillo-Munoz, A. Esteban, I. Inza, L. Abarca and J. Guarro (2002). Collaborative Evaluation of Optimal Antifungal Susceptibility testing Canditions for Dermatophytes, J. Clin. Microbiol. 40, 3999-4003.

[29] M27-S4 - Reference method for broth dilution antifungal susceptibility testing of yeasts (2012), Approved Standard- Third Edition. Clinical and Laboratory Standards Institute, Wayne, Pennsylvania.

[30] H.E. Temel, B. Demirci, F. Demirci, F. Celep, A. Kahraman, M. Doğan and K.H.C. Baser (2016). Chemical characterization and anticholinesterase effects of essential oils derived from Salvia species, J. Essent. Oil Res. 28(4), 322-331.

[31] V.I. Babushok, P.J. Linstrom and I.G. Zenkevich (2011). Retention indices for frequently reported compounds of plant essential oils, J. Phys. Chem. Ref. Data 40(4), 1-47.

[32] G. Özek, Y. Suleimen, N. Tabanca, R. Doudkin, P.G. Gorovoy, F. Goger, D.E. Wedge, A. Ali, I.A. Khan and K.H.C. Baser (2014). Chemical diversity and biological activity of the volatiles of five Artemisia species from far east Russia, Rec. Nat. Prod. 8(3), 242-261.

[33] R.A. Dixon (2001). Natural products and plant disease resistance, Nature 411, 843-847.

[34] M.Z. Haznedaroglu, N.U. Karabay and U. Zeybek (2001). Antibacterial activity of Salvia tomentosa essential oil, Fitoterapia 72, 829-831.

[35] M. Akin, B. Demirci, Y. Bagci and K.H.C. Baser (2010). Antibacterial activity and composition of the essential oils of two endemic Salvia sp. from Turkey, Afr. J. Biotechnol. 9, 2322-2327.

[36] H. Karataş and S. Ertekin (2010). Antimicrobial activities of the essential oils of four Salvia species from Turkey, J. Med. Plants Res. 4, 1238-1240.

[37] A. Ibrahim, A.A. Aqel and A. Aljamal (2013). Effect of the methanol extracts of Salvia libanotica, Rosmarinus officinalis, Capparis spinosa and Achillea fragrantissima against two strains of Staphylococcus aureus, Afr. J. Microbiol. Res. 7(29), 3750-3753.

[38] T. Askun, G. Tumen, F. Satil and M. Ates (2009). Characterization of the phenolic composition and antimicrobial activities of Turkish medicinal plants, Pharm. Biol. 47, 563-571.

[39] T. Askun, K.H.C. Baser, G. Tumen and M. Kurkcuoglu (2010). Characterization of essential oils of some Salvia species and their antimycobacterlal activities, Turk. J. Biol. 34, 89-95.

[40] G.P.P. Kamatou, S.F. van Vuuren, F.R. van Heerden, T. Seaman and A.M. Viljoen (2007). Antibacterial and antimycobacterial activities of South African Salvia species and isolated compounds from S. chamelaeagnea, S. Afr. J. Bot. 73, 552-557.

[41] B. Tepe, D. Daferera, A. Sokmen, M. Sokmen and M. Polissou (2005). Antimicrobial and antioxidant activities of the essential oil and various extracts of Salvia tomentosa Miller (Lamiaceae), Food Chem. 90, 333-340.

[42] M. Sokovic, O. Tzakou, D. Pitarokili and M. Couladis (2002). Antifungal activities of selected aromatic plants growing wild in Greece, Nahrung Food 5, 317-320. 
[43] L. Jirovetz, K. Wlcek, G. Buchbauer, V. Gochev, T. Girova, A. Stoyanova, E. Schmidt and M. Geissler (2007). Antifungal Activities of Essential Oils of Salvia lavandulifolia, Salvia officinalis and Salvia sclarea against Various Pathogenic Candida species, J. Essent. Oil Bear. Pl. 10, 430-439.

[44] G. Topçu and A.C. Gören (2007). Biological Activity of Diterpenoids Isolated from Anatolian Lamiaceae Plants, Rec. Nat. Prod. 1, 1-16.

[45] T. Sookto, T. Srithavaj, S. Thaweboon, B. Thaweboon and B. Shrestha (2013). In vitro effects of Salvia officinalis L. essential oil on Candida albicans, Asian Pac. J. of Trop. Biomed. 3, 376-380.

[46] E. Pinto, L.R. Salgueiro, C. Cavaleiro, A. Palmeira and M.J. Goncalves (2007). In vitro susceptibility of some species of yeasts and filamentous fungi to essential oils of Salvia officinalis, Ind. Crop Prod. 26, 135141.

[47] V. Exarchou, L. Kanetis, Z. Charalambous, S. Apers, L. Pieters, V. Gekas and V. Goulas (2015). HPLCSPE-NMR Characterization of major metabolites in Salvia fruticosa Mill. extract with antifungal potential: relevance of carnosic acid, carnosol, and hispidulin, J. Agr. Food Chem. 63, 457-463.

[48] N. Martins, L. Barros, C. Santos-Buelga, M. Henriques, S. Silva and I.C.F.R. Ferreira (2015). Evaluation of bioactive properties and phenolic compounds in different extracts prepared from Salvia officinalis L., Food Chem. 170, 378-385.

[49] Y. Hristova, V. Gochev, J. Wanner, L. Jirovetz, E. Schmidt, T. Girova and A. Kuzmanov (2013). Chemical composition and antifungal activity of essential oil of Salvia sclarea L. from Bulgaria against clinical isolates of Candida species, J. Bio. Sci. Biotech. 2(1), 39-44.

[50] A. Ulubelen, G. Topçu and C. Bozok-Johansson (1997). Norditerpenoids and Diterpenoids from Salvia multicaulis with Antituberculous Activity, J. Nat. Prod. 60, 1275-1280.

[51] G. Topcu (2006). Bioactive Triterpenoids from Salvia Species, J. Nat. Prod. 69, 482-487.

[52] D. Yang, L. Michel, J.P. Chaumont, J. Millet-Clerc (1999). Use of caryophyllene oxide as an antifungal agent in an in vitro experimental model of onychomycosis, Mycopathologia 148(2), 79-82.

[53] S. Pattnaik, V.R. Subramanyam, M. Bapaji and C.R. Kole (1997). Antibacterial and antifungal activity of aromatic constituents of essential oils, Microbios 89, 39-46.

[54] O. Tzakou, D. Pitarokili, I.B. Chinou and C. Harvala (2001). Composition and antimicrobial activity of the essential oil of Salvia ringens, Planta Med. 67, 81-83.

[55] F. Celep (2010). Revision of The genus Salvia L. (Labiatae) in the mediterranean and the aegean geographic regions of Turkey, $\mathrm{PhD}$ Thesis, Middle East Technical University, Ankara.

[56] M. Doğan, S. Pehlivan, G. Akaydın, E. Bağcı, İ. Uysal and H.M. Doğan (2008). Türkiye'de yayılış gösteren Salvia L. (Labiatae) cinsinin taxonomik revizyonu, Proje No: 104 T 450, Ankara.

[57] G. Flamini, P.L. Cioni, I. Morelli and A. Bader (2007). Essential oils of the aerial parts of three Salvia species from Jordan: Salvia lanigera, S. spinosa and S. syriaca, Food Chem. 100, 732-735.

[58] M.B. Bahadori, H. Valizadeh, B. Asghari, L. Dinparast, M.M. Farimani and S. Bahadori (2015). Chemical composition and antimicrobial, cytotoxicity, antioxidant and enzyme inhibitory activities of Salvia spinosa L., J. Funct. Foods 18, 727-736.

[59] K. Javidnia, R. Miri and A. Jamalian (2005). Composition of the essential oil of Salvia macrosiphon Boiss. from Iran, Flavour Fragr. J. 20, 542-543.

[60] Z. Rajabi, M. Ebrahimi, M. Farajpour, M. Mirza and H. Ramshini (2014). Compositions and yield variation of essential oils among and withinnine Salvia species from various areas of Iran, Ind. Crops Prod. 61, 233239.

[61] F. Salimpour, A. Mazooji and S. Akhoondi Darzikolaei (2011). Chemotaxonomy of six Salvia species using essential oil composition markers, J. Med. Plants Res. 5(9), 1795-1805.

[62] M. Mirza and L. Ahmadi (2000). Composition of the Essential Oil of Salvia atropatana Bunge, J. Bent. Oil Res. 12, 575-576.

[63] M. Altun, M. Ünal, T. Kocagöz and A.C. Gören (2007). Essential oil compositions and antimicrobial activity of Salvia Species, J. Essent. Oil Bear. Pl. 10(3), 251-258.

[64] N. Tan, D. Satana, B. Sen, E. Tan, H. Bardakci-Altan, B. Demirci and M. Uzun (2016). Antimycobacterial and antifungal activities of selected four Salvia species, Rec. Nat. Prod. 10, 593-603.

[65] B. Demirci, K.H.C. Baser, B. Yıldız and Z. Bahçecioğlu (2003). Composition of the essential oils of six endemic Salvia spp. from Turkey, Flavour Fragr. J. 18, 116-121.

[66] S. Nacar and A. Ilcim (2002). Composition of the essential oils of Salvia vermifolia from Turkey, Pharm. Biol. 40(1), 67-69.

[67] F. Senatore, N.A. Arnold, F. Piozzi and C. Formisano (2006). Chemical composition of the essential oil of Salvia microstegia Boiss. et Balansa growing wild in Lebanon, J. Chromatogr. A 1108, 276-278.

[68] S.D. Hatipoglu, N. Zorlu, T. Dirmenci, A.C. Goren, T. Ozturk and G. Topcu (2016). Determination of volatile organic compounds in fourty five Salvia Species by Thermal Desorption-GC-MS Technique. Rec. Nat.Prod. 10, 659-700. 
[69] M. Gulluce, H. Ozer, O. Baris, D. Daferera, F. Şahin and M. Polissiou (2006). Chemical composition of the essential oil of Salvia aethiopis L., Turk. J. Biol. 30, 231-233.

[70] M. Coisin, I. Burzo, M. Ştefan, E. Rosenhech and M.M. Zamfirache (2012). Chemical composition and antibacterial activity of essential oils of three Salvia species, widespread in Eastern Romania, Biol. vegetală 58, 51-58.

[71] M.B. Farhat, A. Landoulsi, R. Chaouch-Hamada, J.A. Sotomayor and M.J. Jordán (2013). Profiling of essential oils and polyphenolics of Salvia argentea and evaluation of its by-products antioxidant activity, Ind. Crops Prod. 47, 106-112.

[72] G. Tel, M. Ozturk, M.E. Duru, M. Harmandar and G. Topcu (2010). Chemical composition of the essential oil and hexane extract of Salvia chionantha and their antioxidant and anticholinesterase activities, Food Chem. Toxicol. 48, 3189-3193.

[73] K.H.C. Baser, B. Dermircakmak and N. Ermin (1996). Essential Oil of Salvia syriaca L., J. Essent. Oil Res. 8, 105-106.

[74] F. Sefidkon and M. Mirza (1999). Chemical composition of the essential oils of two Salvia species from Iran, Salvia virgata Jacq. and Salvia syriaca L., Flavour Fragr. J. 14, 45-46.

[75] M. Jamzad, A. Rustaiyan , Z. Jamzad and S. Masoudi (2011). Essential oil composition of Salvia indica L., Thymus caucasicus Wind. Ex Ronniger subsp. grossheimii (Ronniger) Jalas. and Ballota nigra L. three Labiatae species from Iran, J. Essent. Oil Bear. Pl. 14, 76-83.

[76] D. Pitarokili, M. Couladis, N. Petsikos-Panayotarou and O. Tzakou (2002). Composition and antifungal activity on soil-borne pathogens of the essential oil of Salvia sclarea from Greece, J. Agric. Food Chem. 50, 6688-6691.

[77] A. Džamić, M. Soković, M. Ristić, S. Grujić-Jovanović, J. Vukojević and P.D. Marin (2008). Chemical composition and antifungal activity of Salvia sclarea (Lamiaceae) essential oil, Arch. Biol. Sci. 60, 233-237.

[78] M.E. Duru, G. Tel, M. Ozturk and M. Harmandar (2012). Chemical Composition, antioxidant and anticholinesterase activities of the essential oil of Salvia chrysophylla Staph., Rec. Nat. Prod. 6, 175-179.

[79] M. Kurkcuoglu, B. Demirci, K.H.C. Baser, T. Dirmenci, G. Tumen and U. Ozgen (2005). The essential oil of Salvia limbata C.A. Meyer growing in Turkey, J. Essent. Oil Res. 17, 192-193.

[80] D. Pitarokili, O. Tzakou and A. Loukis (2006). Essential oil composition of Salvia verticillata, S. verbenaca, S. glutinosa and S. candidissima growing wild in Greece, Flavour Fragr. J. 21, 670-673.

[81] M. Couladis, I.B. Chinou, O. Tzakou and A. Loukis (2002). Composition and antimicrobial activity of the essential oil of Ballota pseudodictamnus L. Bentham. Phytother. Res. 16, 723-726.

[82] M.H. Alma, A. Mavi, A. Yildirim, M. Digrak and T. Hirata (2003). Screening chemical composition and in vitro antioxidant and antimicrobial activities of the essential oils from Origanum syriacum L. growing in Turkey, Biol. Pharm. Bull. 26, 1725-1729.

[83] I.H.N. Bassolé, A. Lamien-Meda, B. Bayala, S. Tirogo, C. Franz, J. Novak, R.C. Nebié and M.H. Dicko (2010). Composition and antimicrobial activities of Lippia multiflora Moldenke, Mentha $\mathrm{x}$ piperita L. and Ocimum basilicum L. essential oils and their major monoterpene alcohols alone and in combination, Molecules 15, 7825-7839.

[84] M.H.L. da Silva, E.H.A. Andrade, M.G.B. Zoghbi, A.I.R. Luz, J.D. da Silva and J.G.S. Maia (1999). The essential oils of Lantana camara L. occurring in North Brazil, Flavour Fragr. J. 14, 208-210.

[85] T. Nalina and Z.H.A. Rahim (2007). The crude aqueous extract of Piper betle L. and its antibacterial effect towards Streptococcus mutans, AJBB 3, 10-15.

[86] L. Karcioglu, H. Tanis, N. Comlekcioglu, E. Diraz, E. Kirecci and A. Aygan (2011). Antimicrobial activity of Salvia trichoclada in Southern Turkey, Int. J. Agric. Biol. 13, 134-136.

[87] T. Mojtaba, G.H. Reza, S. Borzo, N. Shiva and S. Esmaeil (2014). In vitro antibacterial and antifungal activity of Salvia multicaulis, J. Essent. Oil Bear. Pl. 14, 255-259.

[88] L. Faheda, D. Stien, N Ouainib, V. Eparvier and M. El Beyrouthy (2016). Chemical diversity and antimicrobial activity of Salvia multicaulis Vahl essential oils, Chem. Biodiversity 13, 591-595.

[89] F. Tosun, C. Akyuz Kizilaya, B. Sener, M. Vural and P. Palittapongarnpim (2004). Antimycobacterial screening of some Turkish plants, J. Ethnopharmacol. 95, 273-275.

[90] B. Sen-Utsukarci, B. Gurdal, M. Bilgin, D. Satana, B. Demirci, N. Tan and A. Mat (2017). Pharmacognostical investigation on Salvia cassia. Nat. Vol. Essent. Oils (NVEO) 4, 23.

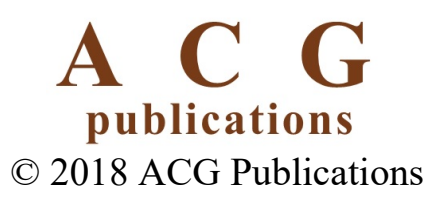

